\title{
Quisqualis indica extract ameliorates low urinary tract symptoms in testosterone propionate-induced benign prostatic hyperplasia rats
}

\author{
Dae-geon Kim ${ }^{1}$, Hyo-Jeong Kwon ${ }^{2}$, Jong-Hwan Lim³ ${ }^{3}$ Joo-heon Kim ${ }^{1,4}$ and Kyu Pil Lee $5^{5^{*}}$
}

\begin{abstract}
Benign prostate hyperplasia (BPH) is a common disease in old-age males, accounting for approximately $77 \%$ of morbidity within the age range of 40 to 70 years. It has been shown that morbidity increases with social graying. Quisqualis indica linn (QI) has been used to treat inflammation, stomach pain, and digestion problems. In this study, we evaluated the symptom-regulating effects of QI extract on a testosteroneinduced $\mathrm{BPH}$ rat model. After inducing BPH in rats using testosterone propionate (TP) injection, we assessed basal intraurethral pressure (IUP) and increments of IUP elicited by electrical field stimulation $(5 \mathrm{~V}, 5,10$, or $20 \mathrm{~Hz}$ ) or phenylephrine (Phe) $(0.01,0.03,0.1 \mathrm{mg} / \mathrm{kg} \mathrm{IV}$ ). To induce $\mathrm{BPH}, 8$-week-old rats were subjected to a daily subcutaneous TP (3 mg/kg) injection for 4 weeks. Finasteride (Fina) $(10 \mathrm{mg} / \mathrm{kg}$ PO) was administered to the rats in the first treatment, while QI $(150 \mathrm{mg} / \mathrm{kg} \mathrm{PO})$ was administered to those in the second group. Blood pressure was measured together with IUP, after which low urinary tract (LUT), ventral prostate (VP), testicle, and corpus spongiosum were isolated and weighed. Basal IUPs for the Fina- and QI-treated groups were 87.6 and $86.8 \%$, respectively.

LUT and VP organ weights in the QI group were lower than those in the Fina group. However, the QI group showed significantly reduced electrical stimulated or Phe-induced IUP increment compared to the Fina and BPH groups. These results proved that QI can be beneficial for BPH symptoms by inhibiting $5 a^{-}$ reductase and consequently decreasing prostate and releasing urinary pressure.
\end{abstract}

Keywords: Benign prostatic hyperplasia, Quisqualis indica, Intraurethral pressure, Lower urinary tract symptoms

\footnotetext{
* Correspondence: kplee@cnu.ac.kr

${ }^{5}$ Department of Veterinary Physiology, College of Veterinary Medicine, Chungnam National University, Daejeon 34134, Republic of Korea

Full list of author information is available at the end of the article
}

C C The Author(s). 2020 Open Access This article is licensed under a Creative Commons Attribution 4.0 International License, which permits use, sharing, adaptation, distribution and reproduction in any medium or format, as long as you give appropriate credit to the original author(s) and the source, provide a link to the Creative Commons licence, and indicate if changes were made. The images or other third party material in this article are included in the article's Creative Commons licence, unless indicated otherwise in a credit line to the material. If material is not included in the article's Creative Commons licence and your intended use is not permitted by statutory regulation or exceeds the permitted use, you will need to obtain permission directly from the copyright holder. To view a copy of this licence, visit http://creativecommons.org/licenses/by/4.0/. The Creative Commons Public Domain Dedication waiver (http://creativecommons.org/publicdomain/zero/1.0/) applies to the data made available in this article, unless otherwise stated in a credit line to the data. 


\section{Introduction}

Benign Prostate Hyperplasia (BPH) is a common disease in old-age males that accounts for $77 \%$ of morbidity within the age range of 40 to 70 years [1]. It has been shown that morbidity increases with social graying [2]. Men with $\mathrm{BPH}$ can experience great discomfort with urination due to urethral obstruction and irritation of the bladder. Obstructive symptoms include decreased voiding power, intermittent urine and delayed urination. Bladder irritation symptoms include frequent urination and nocturnal urination [3]. Although the pathogenesis of $\mathrm{BPH}$ is not fully understood, dihydrotestosterone (DHT) produced by the enzyme $5 \alpha$-reductase, is known as the main mediator of prostatic stromal and epithelial hyperplasia. Enhanced smooth muscle tone in the urethra, prostate, and bladder neck is also the main contributor to voiding symptoms. Therefore, changes in hormones, including the male hormone, and aging are factors responsible for the enlargement of the prostate gland [4].

Treatment of $\mathrm{BPH}$ is mainly through medication. Induction of the relaxation of the prostate smooth muscle by the alpha-adrenergic blocker, restriction of prostate volume using sex hormone suppressors such as $5 \alpha-$ reductase, and relaxation of NO signaling by PDE5 inhibitors are commonly used approaches for $\mathrm{BPH}[5,6]$. When these medications are ineffective, prostate tissues may be surgically resected. However, less invasive and safer alternative therapies are needed due to surgical complications such as bleeding, erectile dysfunction, and urinary incontinence [7].

Traditionally, Quisqualis indica linn (QI) has been used to treat inflammation, stomach pain, and digestion problems [8]. Recently, it has been reported that QI is effective for BPH. It reportedly demonstrated similar efficacy compared to Finasteride at the cellular level, with lesser toxicity at high concentrations [9]. However, no studies have directly measured changes in urethral pressure in response to QI administration in vivo. In this study, we investigated the changes in urethral pressure when QI was administered in testosterone propionate (TP)-induced $\mathrm{BPH}$ rats. We also compared the efficacies of QI and finasteride using outcomes from finasteride- and QI-treated rats. We measured IUP in response to hypogastric nerve stimulation or systemic adrenergic stimulation with phenylephrine (Phe) injection to prove the pharmacological efficacy of QI and to provide preclinical evidence.

\section{Materials and methods}

\section{Preparation of QI extract}

The seeds of Quisqualis indica (QI) were obtained from a local herbal market in Ansan in Korea, authenticated by Dr. Yeon, and deposited at the herbarium of the HUONS Research Center (Voucher No. HU033/SKJA150427) as described previously [9]. The dried seeds were homogenized to a fine powder $(50 \mathrm{~kg})$ and extracted by reflux with $500 \mathrm{~L}$ of $70 \%$ ethanol at $80{ }^{\circ} \mathrm{C}$ for $6 \mathrm{~h}$. The concentration was performed in a vacuum until proper soluble solid-contents were achieved. The concentrated extract was mixed with maltodextrin and subjected to a spray-dryer (ODA-25, SeoGang Engineering, Korea) to obtain the powder from the extract. The standardized QI extract powder contained at least $1 \%$ quisqualic acid, as tested by a validated HPLC assay.

\section{Animals}

Seven-week-old male Sprague-Dawley rats were purchased from Koatech (Pyungteck, South Korea). They were maintained under standard laboratory conditions $\left(22 \pm 2{ }^{\circ} \mathrm{C}\right.$; relative humidity, $50 \pm 5 \%$; $12 \mathrm{~h}$ light/dark cycle), and allowed to consume standard rodent chow and sterilized tap water ad libitum. All animal protocols were approved by the Animal Experimental Ethics Committee of Chungnam National University (CNU-01001, Daejeon, South Korea).

\section{Testosterone propionate-induced $\mathrm{BPH}$ and treatments}

$\mathrm{BPH}$ induction was performed using a modified version of the protocol by Ub Wijerathne, Park et al. [20]. Rats were acclimatized for a week and randomized into 4 groups: (a) normal control (CTRL) group (oral PBS and subcutaneous injection of corn oil); (b) $\mathrm{BPH}$ group $(\mathrm{BPH})$ (oral $\mathrm{PBS}$ and subcutaneous injection of TP $[3 \mathrm{mg} / \mathrm{kg}$ body weight (BW); Tokyo Chemical Ins. Co.]; (c) positive control group (Fina) (oral finasteride $[10 \mathrm{mg} / \mathrm{kg}$ BW; Sigma, St. Louis, MO, U.S.A.] and subcutaneous injection of TP [3 mg/kg BW]); and (d) QI group (QI) (oral QI $[150 \mathrm{mg} / \mathrm{kg} \mathrm{BW]}$ and subcutaneous injection of $\mathrm{TP}[3 \mathrm{mg} / \mathrm{kg} \mathrm{BW}])$. All rats received treatments once per day for 4 weeks.

\section{Measurement of intraurethral pressure}

After BPH was induced and all treatments were provided, intraurethral pressure (IUP) was measured using modified versions of previously described methods [5, 10-12]. After the rats were anesthetized with a combination of urethane $(1000 \mathrm{mg} / \mathrm{kg}$, IP) and alpha-chloralose $(50 \mathrm{mg} / \mathrm{kg}, \mathrm{IP})$, the bladder was exposed through a midline incision in the abdomen. The bladder was cut through the dome and a polyethylene tube (SP45; Natsume, Tokyo, Japan) was inserted towards the bladder neck. A tube with suture was pressed against the outside of the bladder wall near the bladder outlet. Normal saline was 
continuously infused into the intraurethral lumen through the tube at a constant rate $(0.5 \mathrm{~mL} / 10 \mathrm{~min})$ using a NE-4000 syringe pump (New Era Pump Systems, NY, USA). The infusion pressure signals from the urethra were measured using an MLT0699 pressure transducer (AD Instruments, Sydney, NSW, Australia), passed through an amplifier and recorded using a PowerLab 8/35 data acquisition computer system (Software Chart; AD Instruments, Sydney, NSW, Australia). During IUP measurements, the rat was placed on an MP400 warm plate (KITAZATO. Japan) to keep its body temperature at $37^{\circ} \mathrm{C}$. The basal IUP was obtained as an average of $2 \mathrm{~min}(1$ $\mathrm{Hz}$ sampling) of the first point of equilibrium.

\section{Effect of EFS or Phe injection on IUP changes}

For the electrical field stimulating the urethra and surrounding prostate tissue, a pair of fine platinum subdermal needles (Grass, RI, USA) was placed in the abdominal cavity. Urethra and prostate tissue were stimulated using an SD9 electrical stimulator (Grass, RI, USA). The pulse duration was $1 \mathrm{~ms}$, and the amplitude was $5 \mathrm{~V}$. Fifty-second trains of pulses were delivered at 5,10 , and $20 \mathrm{~Hz}$ at approximately 2-min intervals.

For injection of Phe, a 26-G catheter (BD. Singapore), and heparin cap (BD. Singapore) were placed in the femoral vein. Phe was injected sequentially through the heparin cap at concentrations of $0.01 \mathrm{mg} / \mathrm{kg}, 0.03 \mathrm{mg} / \mathrm{kg}$, and $0.1 \mathrm{mg} / \mathrm{kg}$. The changes in IUP after Phe injection were evaluated as changes in peak $(\Delta$ peak $)$ and changes in mean IUP $(\Delta$ average) for time to baseline recovery. All IUP changes were measured using the level before EFS or the injection of Phe was given as the baseline.

\section{Measurement of blood pressure}

The changes in BP, and associated changes in IUP, were evaluated by a direct method. An incision was made on the left or right side of the neck to expose the common carotid artery. The cranial part of the exposed artery was ligated twice with 3-0 silk (Ailee, Busan, Korea), and a 26-G catheter (BD, Singapore) was inserted into the blood vessel. The catheter was connected to an MLT0699 pressure transducer (AD Instruments, Sydney, NSW, Australia) using a polyethylene tube (SP45; Natsume, Tokyo, Japan). This was the same as the measurement of the IUP, and the measured pressure was evaluated by averaging five systolic BP per individual animal.

\section{Measurement of organ weight}

Low urinary tract (LUT), ventral prostate (VP), testicle and corpus spongiosum (CS) were isolated and weighed by autopsy after IUP was measured. All organ weights were presented as percentages of body weight.

\section{Measurement of CRP}

Blood samples (approximately $2 \mathrm{~mL}$ ) from the cervical artery were collected and placed in a tube containing sodium heparin (15-20 U) during the autopsy. They were centrifuged at $3000 \mathrm{rpm}$ for $5 \mathrm{~min}$ to obtain plasma. The obtained plasma was stored at $-80^{\circ} \mathrm{C}$ until CRP measurement. Serum CRP was analyzed with a sandwich enzyme-linked immunosorbent assay (ELISA) using a highly sensitive rat sample CRP ELISA kit (LS-F9616, LS bio, USA, Seattle) and microplate absorbance reader (Infinite 200pro, Tecan, Switzerland). The reaction of the rat CRP antibody was evaluated using streptavidin-horseradish peroxidase (HRP). The tetra-methyl benzidine reaction with HRP bound to the immune complex was measured at $450 \mathrm{~nm}$ absorbance. The absorbance results were calculated using the four-parameter logistic standard curve fit.

\section{Isometric contractile recording of ventral prostate tissue ex vivo}

Before each experiment, the male SD rats were sacrificed by cervical dislocation following anesthesia using carbon dioxide. The abdominal cavity was immediately opened by midline laparotomy and the urogenital complex was obtained. The urogenital complex was removed from capsular fiber tissues and seminal vesicles. The ventral lobular was excised in strips (approximately $4-\mathrm{mm}$ wide and $10-\mathrm{mm}$ long in ice-cold physiological saline solution (PSS) consisting of $120 \mathrm{mM} \mathrm{NaCl}, 2.5 \mathrm{mM} \mathrm{CaCl}_{2}, 1.2 \mathrm{mM} \mathrm{MgCl} 2,11$ $\mathrm{mM}$ glucose, $25 \mathrm{mM} \mathrm{NaHCO}, 5.9 \mathrm{mM} \mathrm{KCl}$, and 1.2 $\mathrm{mM} \mathrm{NaH} \mathrm{PO}_{4} \cdot \mathrm{H}_{2} \mathrm{O}$. It was also continuously bubbled with $5 \% \mathrm{CO}_{2}$ and $95 \%$ oxygen. The solution was aerated with $95 \%$ oxygen and $5 \% \mathrm{CO} 2$, and warmed $37^{\circ} \mathrm{C}$ at $\mathrm{pH}$ 7.4. One side of the tissue was connected to the holder, and the other end was connected to an isometric force transducer (FT03, Grass). The collected signal was amplified and converted to a digital signal using a Powerlab system (Powerlab 8/30. ADI instrument, USA). Finally, the collected signal was recorded using the LabChart 8.0 (ADinstrument) program.

\section{Statistical analysis}

All data are expressed as the mean \pm standard error of the mean (S.E.M.). Data were analyzed by one-way ANOVA using Origin 8.0 software (OriginLab, MA, USA). A $p$-value below 0.05 was considered statistically significant. 


\section{Results}

Treatment effects of IUP baseline changes

The effect of $\mathrm{BPH}$ induction and QI administration on baseline IUP was measured (Fig. 1). Baseline IUP for the $\mathrm{BPH}$-induced group $(\mathrm{BPH})$ was $41.99 \pm 3.11$ $\mathrm{mmHg}$, which was higher than $31.63 \pm 2.61 \mathrm{mmHg}$ measured for the control group. However, in the BP- induced group treated with Fina, there was a tendency for was $36.80 \pm 2.12 \mathrm{mmHg} \quad(n=8, \quad P$ value< 0.05$)$. IUP was $36.45 \pm 1.30 \mathrm{mmHg}$ in the $\mathrm{BPH}$-induced group treated with QI, which was similar to the Fina group. The QI and Fina groups showed similar inhibition of $\mathrm{BPH}$-induced elevation of urethral pressure.

\section{Effects of Phe injection on IUP changes}

We examined the changes in IUP for alphaadrenergic stimulation induced by Phe administration in each group. In the $0.01 \mathrm{mg} / \mathrm{kg}$ Phe administered group, the peak values of IUP were $6.19 \pm 1.55 \mathrm{mmHg}$, $11.67 \pm 4.14 \mathrm{mmHg}, \quad 10.16 \pm 1.99 \mathrm{mmHg}$, and $9.31 \pm$ $2.31 \mathrm{mmHg}$ for CTRL, BPH, Fina, and QI groups respectively. In the $0.03 \mathrm{mg} / \mathrm{kg}$ Phe administrated group, peak values of IUP were $8.74 \pm 3.42 \mathrm{mmHg}$,
$16.53 \pm 5.98 \mathrm{mmHg}, \quad 17.89 \pm 3.79 \mathrm{mmHg}$ and $12.52 \pm$ $3.06 \mathrm{mmHg}$ for CTRL, BPH, Fina and QI groups respectively. In the case of $0.1 \mathrm{mg} / \mathrm{kg}$ Phe administration, $14.89 \pm 6.39 \mathrm{mmHg}, 22.09 \pm 4.08 \mathrm{mmHg}, 23.20 \pm$ $6.26 \mathrm{mmHg}$ and $15.53 \pm 5.51 \mathrm{mmHg}$ peak values of IUP were recorded for CTRL, BPH, Fina and QI groups respectively (Fig. 2b). The concentration of Phe injected was directly proportional to IUP. The increment in the IPU of the QI-treated group was significantly reduced compared to the increment in the Fina group.

\section{Effects of EFS on IUP changes}

We also examined the effect of hypogastric nerve stimulation on IUP in each group (Fig. 3). For stimulation at $5 \mathrm{~Hz}$, the values for the CTRL, BPH, Fina, and QI groups were $1.08 \pm 0.12 \mathrm{mmHg}, 1.98 \pm 0.33$ $\mathrm{mmHg}, \quad 1.33 \pm 0.27 \mathrm{mmHg}$ and $1.01 \pm 0.11 \mathrm{mmHg}$, respectively. For the stimulation at $10 \mathrm{~Hz}$, the values were $1.22 \pm 0.16 \mathrm{mmHg}, \quad 1.72 \pm 0.28 \mathrm{mmHg}, \quad 1.49 \pm$ $0.23 \mathrm{mmHg}$ and $1.25 \pm 0.17 \mathrm{mmHg}$ for CTRL, BPH, Fina, and QI respectively. At $20 \mathrm{~Hz}, 1.47 \pm 0.21$ $\mathrm{mmHg}, \quad 2.16 \pm 0.31 \mathrm{mmHg}, \quad 1.82 \pm 0.22 \mathrm{mmHg}$ and $1.38 \pm 0.12 \mathrm{mmHg}$ were measured for CTRL, BPH,

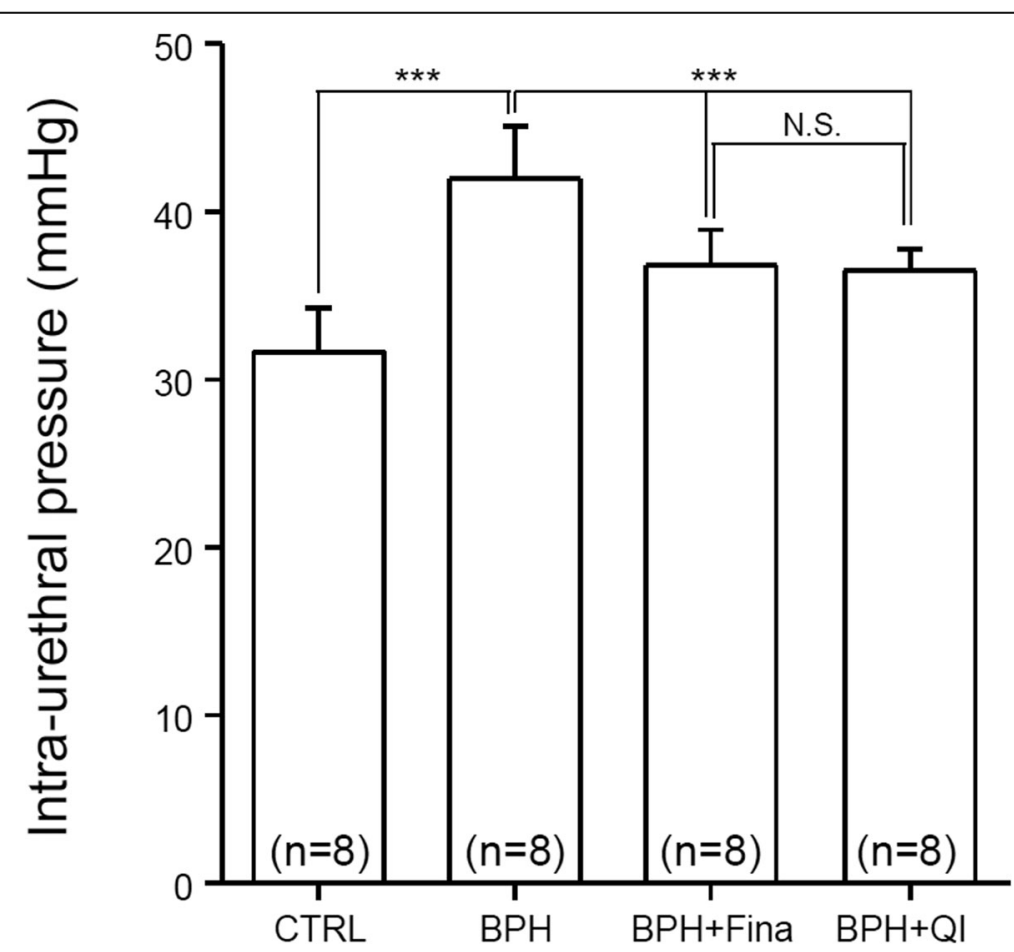

Fig. 1 Effects of Q extract and Finasteride on basal IUP in anesthetized BPH-induced model rats. The basal IUP is derived from an average of 2 min (1 Hz sampling) of the first point of equilibrium. CTRL, Vehicle-treated animal; BPH, BPH-induced and non-treated animal; BPH + Fina, BPH induced and Finasteride (10 mg/kg/day, Oral) treated animals; BPH + QI, BPH induced and QI (150 mg/kg/day, Oral) - treated animals. Column and bars represent the mean and SEM $\left({ }^{* * *} P<0.001\right)$ 


\section{A}

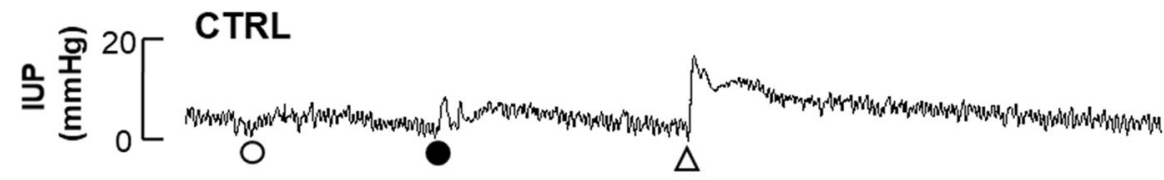

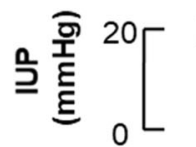

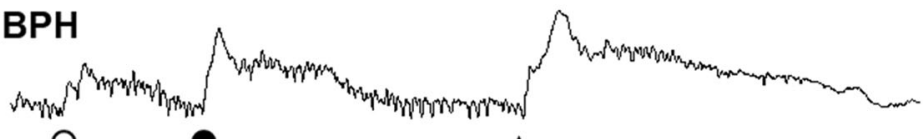

ํㅗㄹ ${ }_{\text {है }}^{\text {है }}{ }_{0}^{20}[$

\section{BPH + Fina}

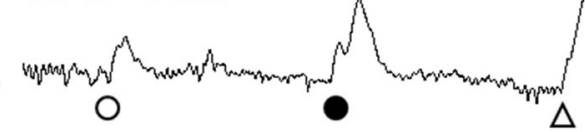

$\triangle$

올 ${ }_{0}^{\frac{\text { ⿱ㅗ }}{\xi}}{ }_{0}^{20}[$

$\mathrm{BPH}+\mathrm{QI}$

B

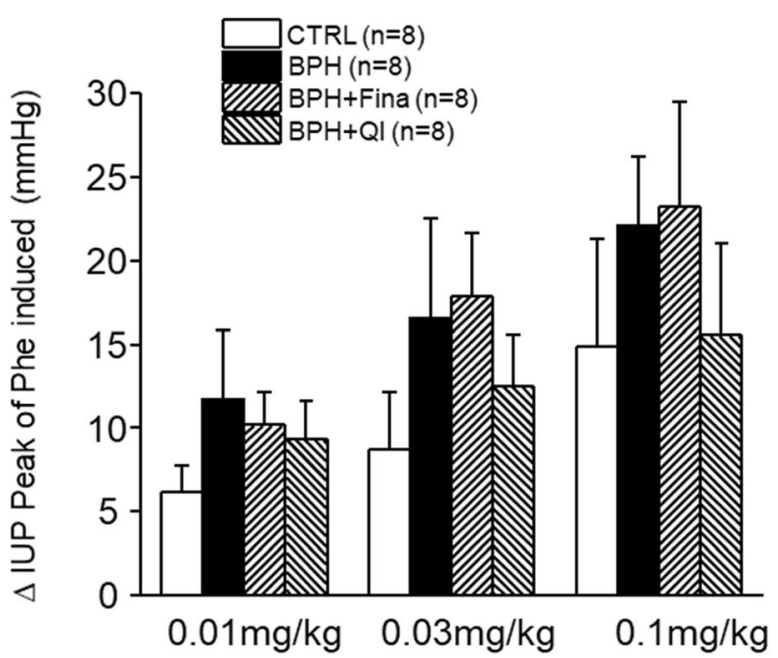

Fig. 2 Effects of QI extract and Finasteride on electrostimulation $(5 \mathrm{~V}, 5,10,20 \mathrm{~Hz})$ induced an increase in IUP in anesthetized BPH-induced model rats. Urethra and surrounding prostate tissue were stimulated by a pair of fine platinum subdermal needles. CTRL, Vehicle-treated animal; BPH, BPH-induced and non-treated animal; BPH + Fina, BPH-induced and Finasteride (10 mg/kg/day, Oral)-treated animals; BPH + QI, BPH induced and QI $\left(150 \mathrm{mg} / \mathrm{kg} /\right.$ day, Oral)-treated animals. Each column and bars represent the mean and SEM $\left({ }^{*} P<0.05\right)$

Fina and QI respectively. Compared to CTRL, the response of the BPH group to the stimulation of $5 \mathrm{~Hz}$ EFS was significantly increased $(P<0.05)$. The Fina and QI groups, however, still showed a similar increase compared to CTRL.

\section{Effects of Fina and QI on BP}

We evaluated changes in blood pressure in each group. The systolic BP of the CTRL, BPH, Fina, and QI groups were $135.40 \pm 2.16 \mathrm{mmHg}, \quad 129.86 \pm 3.58$
$\mathrm{mmHg}, 133.54 \pm 3.49 \mathrm{mmHg}$, and $124.33 \pm 3.20 \mathrm{mmHg}$ respectively (Fig. 4). There were no significant statistical differences between the CTRL, BPH, and Fina groups, but the QI group showed a significant decrease in systolic BP $(P<0.05)$. Therefore, QI has no adverse effects on the cardiovascular system.

Effect of QI on the weight of male reproductive organs We examined the ratio of LUT, VP, testicle, and CS for each organ relative to body weight. CTRL, BPH, 


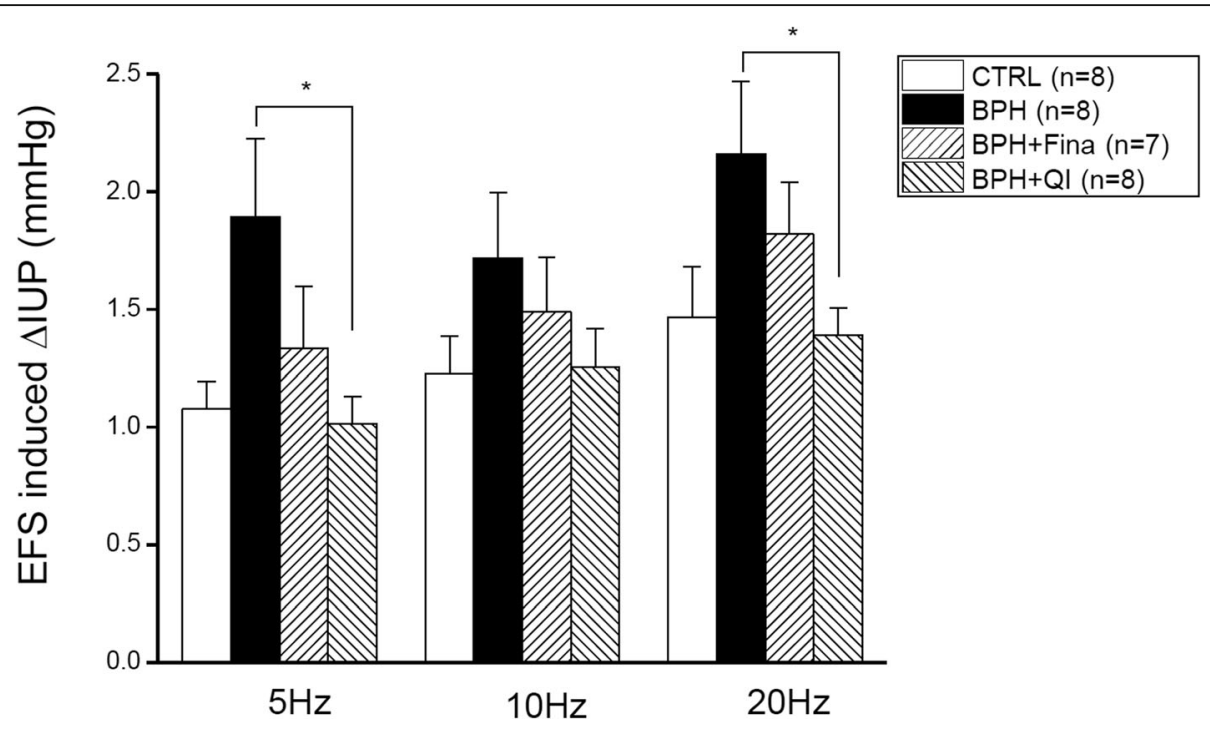

Fig. 3 Effects of Ql extract and Finasteride on intraurethral pressure increase peak and average value induced by acute Phe injection in anesthetized BPH-induced model rats. a Representative traces of each control and treatment group. $\mathbf{b}$ The intraurethral pressure increases the peak value induced by Phe $(0.01,0.03,0.1 \mathrm{mg} / \mathrm{kg} \mathrm{IV})$. CTRL, Vehicle-treated animal; BPH, BPH-induced and non-treated animal; BPH + Fina, BPH induced and Finasteride (10 mg/kg/day, Oral) treated animals; BPH + Ql, BPH induced and QI (150 mg/kg/day, Oral)-treated animals. Each column and bars represent the mean and SEM

Fina, and QI recorded LUT values of $0.624 \pm 0.020 \%$, $1.563 \pm 0.026 \%, \quad 1.176 \pm 0.031 \%$, and $1.457 \pm 0.028 \%$ respectively (Fig. 5a). LUT weight was significantly decreased in the Fina group, but increased in the $\mathrm{BPH}$ group $(P<0.001)$. The QI groups also recorded decreased LUT weight, but it was less statistically significant $(P<0.05)$. Finely dissected VP weights were measured, and the values were $0.108 \pm 0.006 \%$, $0.298 \pm 0.015 \%, 0.198 \pm 0.012 \%$, and $0.240 \pm 0.009 \%$ for CTRL, BPH, Fina, and QI respectively, (Fig. 5b). The weight of VP of the Fina group was significantly lower compared to the $\mathrm{BPH}$ group $(p<0.001)$. The

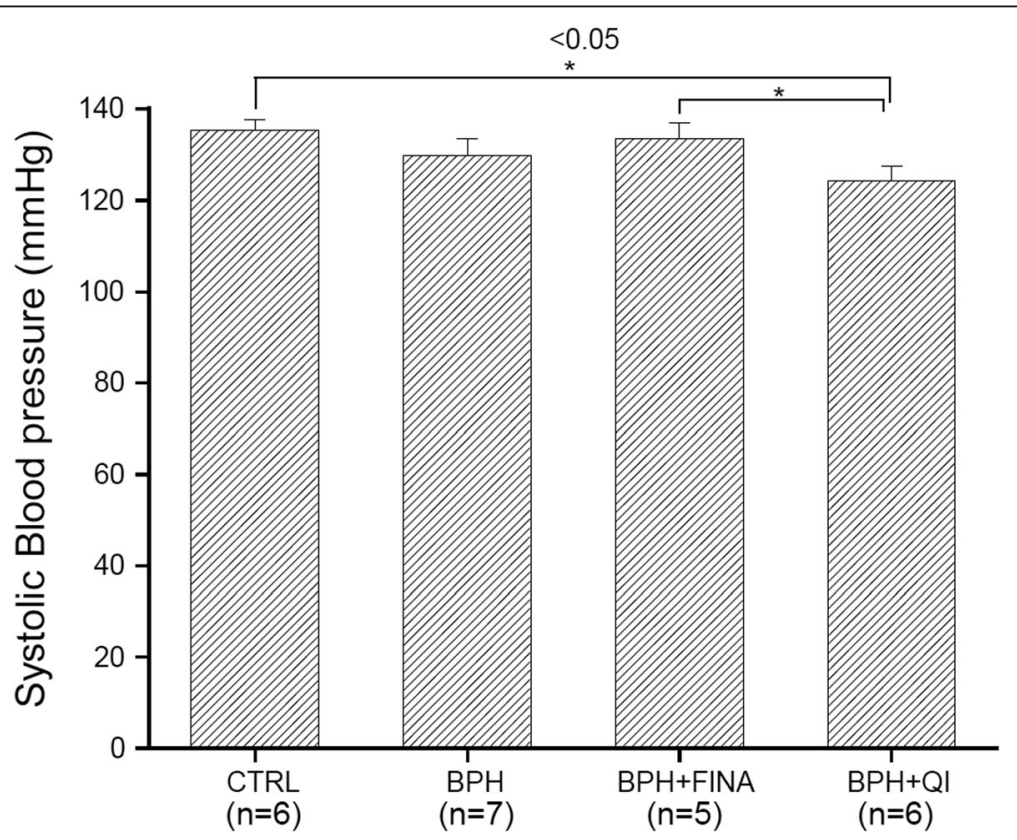

Fig. 4 Effects of $\mathrm{QI}$ extract and Finasteride on systolic BP in anesthetized BPH-induced model rats. CTRL, Vehicle-treated animal; $\mathrm{BPH}$, BPH-induced and non-treated animal; BPH + Fina, BPH induced and Finasteride (10 mg/kg/day, Oral) treated animals; BPH + QI, BPH induced and QI (150 mg/ $\mathrm{kg} / \mathrm{day}$, Oral)-treated animals. Each column and bars represent the mean and SEM $\left.{ }^{*} P<0.05\right)$ 

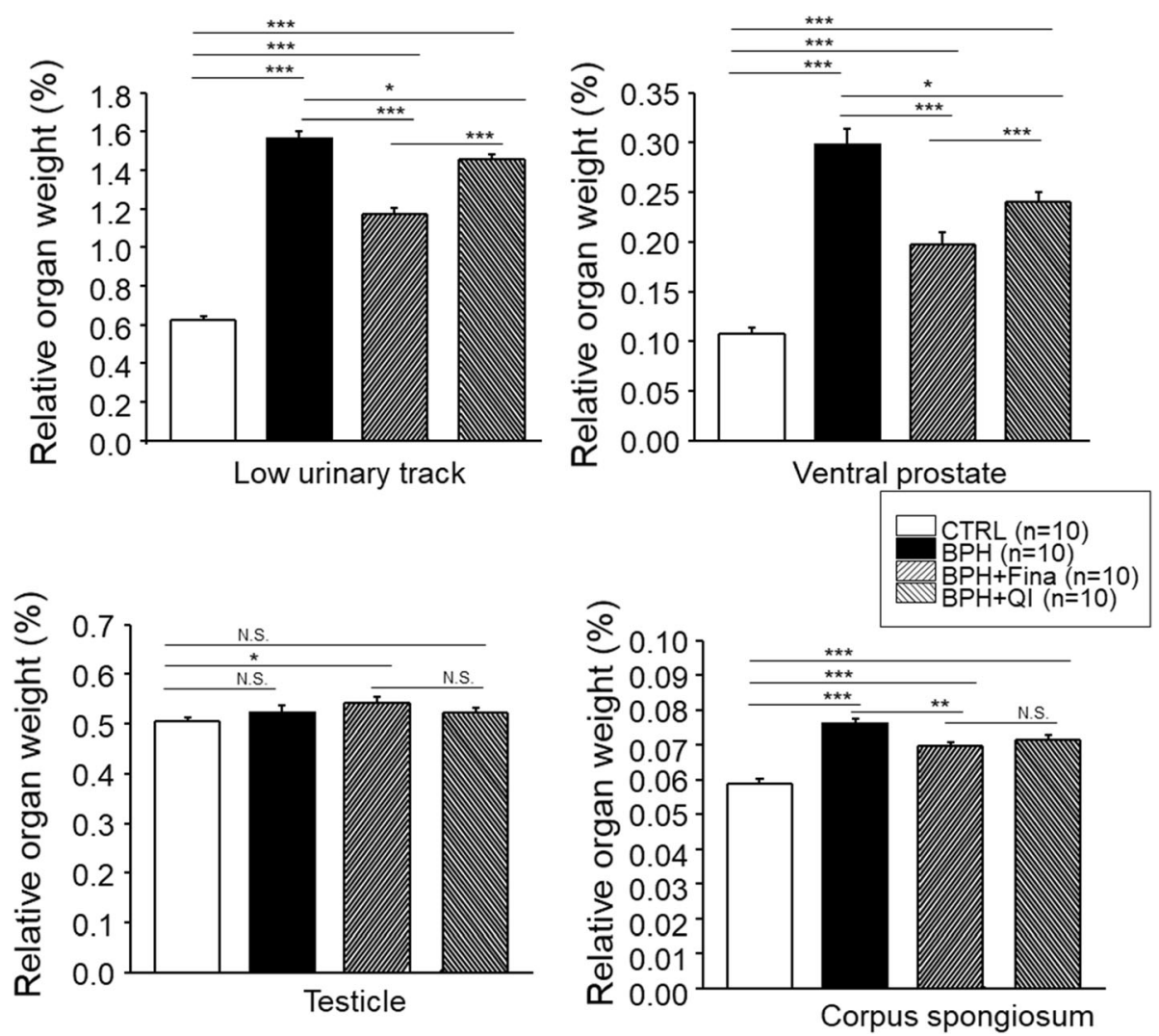

Fig. 5 Effects of Ql extract and Finasteride on the weight of various organs in control and treatment groups. The ratio of relative organ weight a low urinary tract, $\mathbf{b}$ ventral prostate, $\mathbf{c}$ testicular, $\mathbf{d}$ corpus spongiosum. CTRL, Vehicle-treated animal; BPH, BPH-induced and non-treated animal; $\mathrm{BPH}+$ Fina, BPH induced and Finasteride $(10 \mathrm{mg} / \mathrm{kg} /$ day, Oral) treated animals; BPH + QI, BPH induced and QI (150 mg/kg/day, Oral)-treated animals. Each column and bars represent the mean and SEM $\left({ }^{*} P<0.05,{ }^{* *} P<0.01,{ }^{* *} P<0.001\right)$

weight of VP in the QI group was significantly decreased $(P<0.05)$. The weights of testicles in CTRL, $\mathrm{BPH}$, Fina, and QI groups were $0.504 \pm 0.009 \%$, $0.524 \pm 0.014 \%, \quad 0.542 \pm 0.012 \%$, and $0.521 \pm 0.012 \%$, respectively (Fig. 5c). There were no significant differences in testicle weight between the treated groups. The weights of CS were $0.059 \pm 0.001 \%$, $0.076 \pm 0.001 \%, 0.070 \pm 0.001 \%$, and $0.072 \pm 0.001 \%$ for CTRL, BPH, Fina, and QI, respectively (Fig. 5d). No significant difference was found between the Fina and QI groups, But the weight was greater in CS than in the CTRL group $(P<0.001)$.

\section{Effects of QI on serum CRP concentration}

The concentration of serum CRP was measured. Serum CRP concentration was significantly higher in the BPH $(P<0.05)$ than in the control group (Fig. 6). Serum CRP concentration was not significantly different in the Fina and BPH groups. The CRP concentrations in the QI groups were significantly lower compared to the $\mathrm{BPH}$ group $(P<0.05)$. The concentrations were $124.10 \pm 21.87,909.83 \pm 67.91,773.79 \pm 127.15$, and $632.63 \pm 38.98 \mu \mathrm{g} / \mathrm{mL}$ for the CTRL, BPH, Fina, and QI groups, respectively (Fig. 6).

\section{Effects of QI on ventral prostate smooth muscle strip}

We examined the effect of QI extract on Phe-induced contraction of the ventral prostate smooth muscle strip to test immediate action on prostate relaxation and its contribution to IUP release. Vehicle (DMSO); $7 \mathrm{mg} / \mathrm{mL} /$ $\mathrm{mL}$, and $14 \mathrm{mg} / \mathrm{mL}$ of QI extract were added in the precontracted ventral prostate smooth muscle strip with $1 \mu \mathrm{M}$ Phe. In the CTRL group, $83.78 \pm 1.68 \%$ of maximal contraction remained after $5 \mathrm{~min}$ of treatment. Treatment with $7 \mathrm{mg} / \mathrm{mL}$ and $14 \mathrm{mg} / \mathrm{mL}$ QI reduced this to $79.61 \pm 1.79 \%$ and $73.74 \pm 1.09 \%$ respectively $(n=5-8$, $p<0.01)$. Therefore, QI extract can inhibit Phe-induced contraction of ventral prostate smooth muscle in high concentrations (Fig. 7).

\section{Discussion}

The prostate surrounds the neck of the bladder and urethra, and plays an important role in the male 


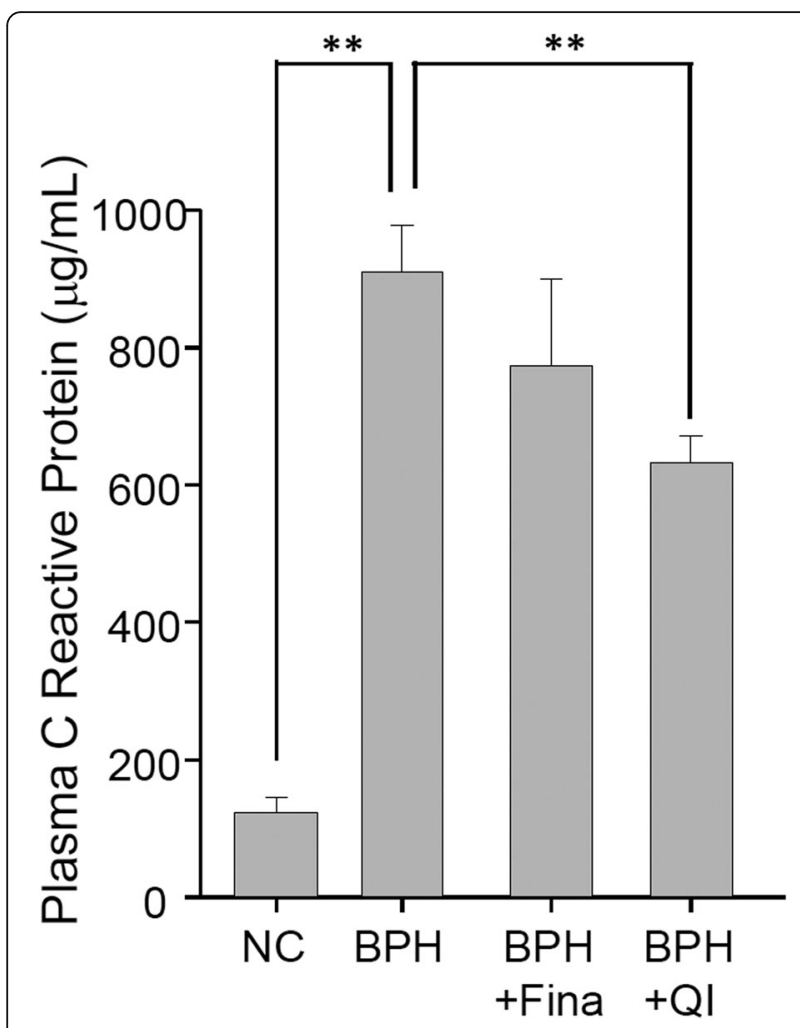

Fig. 6 Effects of QI on serum C-reactive protein (CRP) concentration in serum. CTRL, Vehicle-treated animal; BPH, BPH-induced and nontreated animal; BPH + Fina, BPH induced and Finasteride $(10 \mathrm{mg} / \mathrm{kg} /$ day, Oral) treated animals; BPH + QI, BPH induced and QI (150 mg/ $\mathrm{kg} / \mathrm{day}$, Oral)-treated animals. Each column and vertical bar represents the mean and SEM (** $P<0.01)$

reproductive system [13]. Enlargement of the prostate can cause lower urinary tract symptoms such as urinary tract obstruction, urinary tract infection, bladder function depression, and erectile dysfunction due to the proliferation of the prostate tissue and compression of the urethra [14].

A recent study by Ub Wijerathne et al. demonstrated that QI reduced the epithelial hyperplasia of the prostate, blood testosterone, DHT in prostate tissue, and $5 \alpha$-reductase [9]. Baek et al. also proposed the attenuation of prostatic hyperplasia via possible interactions of QI with $\alpha 1$ adrenergic receptor and androgen receptor [15]. These two studies evaluated the mechanisms of action of QI, but we confirmed in our study that QI could mitigate the increase in urethral pressure, which is the biggest practical symptom of enlarged prostate at effective doses in BPH rat models. The basal urethral pressure, adrenergic stimulatedelevation, and hypogastric nerve stimulated-elevation of intraurethral pressure were reduced in the QItreated animals. We also confirmed that QI can reduce systemic CRP concentration. Systolic blood pressure, however, was not significantly reduced.
Dihydrotestosterone (DHT) increases in the prostate, although serum testosterone levels decrease with age. It has been reported that the activity of $5 \alpha$-reductase, which converts testosterone to DHT, was increased in BPH [16]. Therefore, $5 \alpha$-reductase inhibitors, such as finasteride or dutasteride, have been widely used in treating BPH [17]. Previously, Wijerathene et al. showed that QI extract inhibited $5 \alpha$ reductase type 2 , cyclin $\mathrm{D} 1$, and caspase- 3 . Therefore, it is not surprising that QI extract reduced intraurethral pressure to ameliorate low urinary tract symptoms. As expected, QI treatment reduced the whole lower urinary tract as well as the ventral prostate in the relative organ weight, and intraurethral pressure. Although the rat prostate cannot surround the urethra as observed in humans, dorsal and ventral prostate enlargement can cause incomplete urinary voiding and increase the frequency of micturition [18].

QI extract alleviated intraurethral pressure in response to Phe administration compared to the $\mathrm{BPH}$ group, and IUP increased similarly in the QI and control groups as Phe concentration was increased in the QI group. This suggests that the administration of QI inhibits $\alpha$ adrenergic receptors in the prostate in vivo, while isolated ventral prostatic smooth muscle strips were only relaxed in high concentrations of QI treatment. The use of conventional $\alpha 1$-adrenoceptor antagonists that are structurally related (e.g., tamsulosin and indoramin) to prazosin could be limited by drug-related adverse cardiovascular effects, such as orthostatic hypotension [19]. The low selectivity of the receptor subtypes of $\alpha$ adrenergic receptor inhibitors can lead to dizziness due to vasodilation [20]. However, QI treatment did not affect BP. The systolic blood pressure of the QI group was lower than that of the CTRL group, and this is thought to be due to the antagonistic effects on androgen receptors. This suggests that QI mitigates the symptoms of $\mathrm{BPH}$ without side effects on the cardiovascular system.

\section{Conclusions}

Alpha-blockers are believed to improve symptoms and flow rate by inducing relaxation of the smooth muscle neck and prostate area (dynamic component), while $5 \alpha$-reductase inhibitors are believed to improve symptoms and flow rate by shrinking the transition zone of the prostate through hormonal mechanisms (static component). Therefore, combined therapy using $\alpha 1$ adrenergic blocker and $5 \alpha$-reductase inhibitor may be more effective in relieving and preventing the progression of symptoms [21]. QI administration can result in symptomatic improvement in $\mathrm{BPH}$. The 


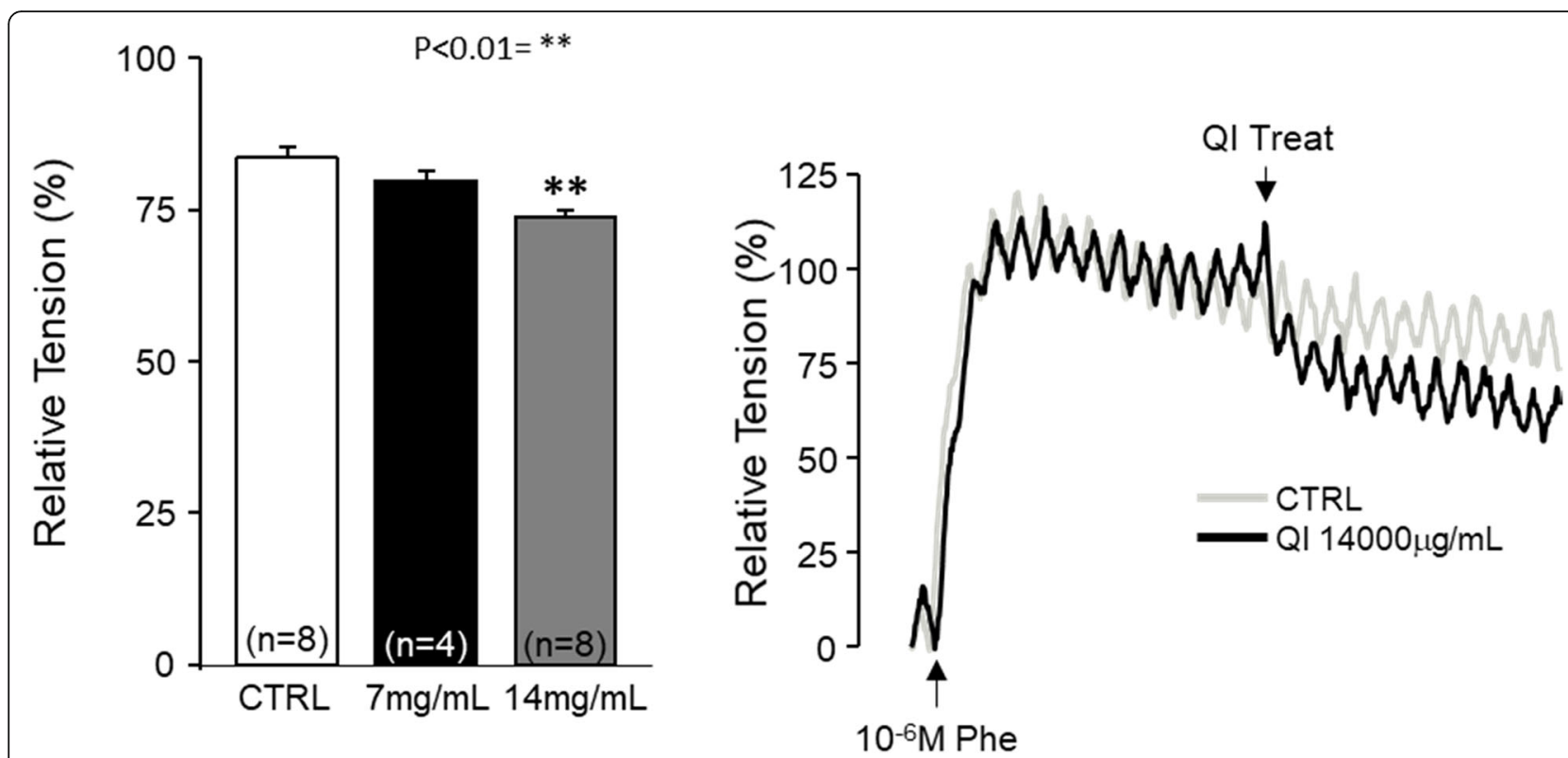

Fig. 7 Effects of Ql extract on phenylephrine precontracted ventral prostate strips a), control vehicle (CTRL), $7 \mathrm{mg} / \mathrm{mL}$, and $14 \mathrm{mg} / \mathrm{mL} \mathrm{Q}$ extracts were treated in the rat ventral prostate strip pre-contracted with $1 \mu \mathrm{M}$ Phe. $\mathbf{b}$ Representative trace of effects of Ql extract on Phe induced contraction on the ventral prostate strip. Each column and vertical bar represents the mean and SEM (**P $<0.01)$

mechanism of action of QI may be via inhibition of the $5 \alpha$ reducing activity with mild inhibition of $\alpha 1$ adrenergic receptor at the systemic level. Therefore, QI extract can significantly improve symptoms of $\mathrm{BPH}$ with fewer adverse effects and may also be used as a dietary supplement for prostate health.

\section{Abbreviations}

BPH: Benign prostate hyperplasia; QI: Quisqualis indica linn; TP: Testosterone propionate; IUP: Intraurethral pressure; Phe: Phenylephrine; Fina: Finasteride; LUT: Which low urinary tract; VP: Ventral prostate; CS: Corpus spongiosum;

DHT: Dihydrotestosterone; CRP: C-reactive protein; DMSO: Dimethyl sulfoxide

\section{Acknowledgements}

Not applicable.

\section{Authors' contributions}

KDG, KHJ, LJH and LKP performed experiment and data analysis and $\mathrm{KH}$, KDG, KHJ, LJH and LKP wrote the manuscript. The author(s) read and approved the final manuscript.

\section{Funding}

This work was supported by a grant from the Korean Institute of Planning and Evaluation for Technology in Food, Agriculture, Forestry and Fisheries (IPET) through Agri-Bio Industry Technology Development Program (2016190262), funded by Ministry of Agriculture, Food and Rural Affairs (MAFRA).

\section{Availability of data and materials}

The data that support the findings of this study are available on request from the corresponding author on reasonable request.

\section{Competing interests}

The authors declare no competing interests.

\section{Author details}

'Department of Veterinary Physiology, College of Veterinary Medicine,

Gyeongsang National University, Jinju 52828, Republic of Korea. ${ }^{2}$ Department of Veterinary Pathology, College of Veterinary Medicine, Chungnam National University, Daejeon 34134, Republic of Korea. ${ }^{3}$ Huons Research Center, Ansan, Gyeonggi-do 15588, Republic of Korea. ${ }^{4}$ Institute of Animal Medicine, College of Veterinary Medicine, Gyeongsang National University, Jinju 52828, Republic of Korea. ${ }^{5}$ Department of Veterinary Physiology, College of Veterinary Medicine, Chungnam National University, Daejeon 34134, Republic of Korea.

Received: 14 May 2020 Accepted: 27 July 2020

Published online: 08 August 2020

\section{References}

1. Barkin J. Benign prostatic hyperplasia and lower urinary tract symptoms: evidence and approaches for best case management. Can J Urol. 2011; 18(1):14.

2. Carruthers SG. Adverse effects of a 1-adrenergic blocking drugs. Drug Saf. 1994;11(1):12-20.

3. Choi BR, Soni KK, Zhang LT, Lee SW, So I, Kim HK, Park JK. Effect of 4-chloro7-trifluoromethyl-10H-benzo [4,5] furo [3,2-b]indole-1-carboxylic acid on the intraurethral pressure in a rat model of benign prostatic hyperplasia. Int J Urol. 2016;23(3):259-65.

4. Desgrandchamps F. Who will benefit from combination therapy? The role of 5 alpha reductase inhibitors and alpha blockade: a reflection from MTOPS. Curr Opin Urol. 2004;14(1):17-20.

5. Fwu C-W, Eggers PW, Kirkali Z, McVary KT, Burrows PK, Kusek JW. Change in sexual function in men with lower urinary tract symptoms/benign prostatic hyperplasia associated with long-term treatment with doxazosin, finasteride and combined therapy. J Urol. 2014;191(6):1828-34.

6. Girman C. Population-based studies of the epidemiology of benign prostatic hyperplasia. Br J Urol. 1998;82:34.

7. Kambar Y, Asha M, Chaithra M, Kekuda PT. Antibacterial activity of leaf and flower extract of Quisqualis indica Linn. against clinical isolates of Staphylococcus aureus. Res J Sci Technol. 2014;6(1):23.

8. Kang KK, Kim JM, Yu JY, Ahn BO, Yoo M, Kim YC. Effects of phosphodiesterase type 5 inhibitor on the contractility of prostate tissues and urethral pressure responses in a rat model of benign prostate hyperplasia. Int J Urol. 2007;14(10):946-51 discussion 951. 
9. Kontani H, Shiraoya C. Method for simultaneous recording of the prostatic contractile and urethral pressure responses in anesthetized rats and the effects of tamsulosin. Jpn J Pharmacol. 2002;90(3):281-90.

10. McVary KT. Erectile dysfunction and lower urinary tract symptoms secondary to BPH. Eur Urol. 2005;47(6):838-45.

11. McVary KT, Roehrborn CG, Avins AL, Barry MJ, Bruskewitz RC, Donnell RF, Foster HE, Gonzalez CM, Kaplan SA, Penson DF. Update on AUA guideline on the management of benign prostatic hyperplasia. J Urol. 2011;185(5): 1793-803.

12. Mebust W, Holtgrewe H, Cockett A, Peters P. Transurethral prostatectomy: immediate and postoperative complications. Cooperative study of 13 participating institutions evaluating 3,885 patients. J Urol. 2002;167(1):5-9.

13. Mondaini N, Gontero P, Giubilei G, Lombardi G, Cai T, Gavazzi A, Bartoletti R. Finasteride $5 \mathrm{mg}$ and sexual side effects: how many of these are related to a nocebo phenomenon? J Sex Med. 2007:4(6):1708-12.

14. Nascimento-Viana JB, Carvalho AR, Nasciutti LE, Alcantara-Hernandez R, Chagas-Silva F, Souza PA, Romeiro LA, Garcia-Sainz JA, Noel F, Silva CL. New multi-target antagonists of alpha1A-, alpha1D-adrenoceptors and 5-HT1A receptors reduce human hyperplastic prostate cell growth and the increase of intraurethral pressure. J Pharmacol Exp Ther. 2016;356(1):212-22.

15. Oh SH, Oh BR, Ryu SB. Effect of finasteride on sexual function in patients with benign prostatic hyperplasia. Korean J Urol. 2002;43(7):611-8.

16. Patel ND, Parsons JK. Epidemiology and etiology of benign prostatic hyperplasia and bladder outlet obstruction. Indian J Urol. 2014;30(2):170

17. Roehrborn C. Pathology of benign prostatic hyperplasia. Int J Impot Res. 2008;20(S3):S11.

18. Roehrborn CG, Casabé A, Glina S, Sorsaburu S, Henneges C, Viktrup L. Treatment satisfaction and clinically meaningful symptom improvement in men with lower urinary tract symptoms and prostatic enlargement secondary to benign prostatic hyperplasia: secondary results from a 6 month, randomized, double-blind study comparing finasteride plus tadalafil with finasteride plus placebo. Int J Urol. 2015;22(6):582-7.

19. Rosen R, Altwein J, Boyle P, Kirby RS, Lukacs B, Meuleman E, O'Leary MP, Puppo P, Robertson C, Giuliano F. Lower urinary tract symptoms and male sexual dysfunction: the multinational survey of the aging male (MSAM-7). Eur Urol. 2003;44(6):637-49.

20. Ub Wijerathne C, Park H-S, Jeong H-Y, Song J-W, Moon O-S, Seo Y-W, Won Y-S, Son H-Y, Lim J-H, Yeon S-H, Kwun H-J. Quisqualis indica improves benign prostatic hyperplasia by regulating prostate cell proliferation and apoptosis. Biol Pharm Bull. 2017;40(12):2125-33.

21. Walsh P, Hutchins G, Ewing L. Tissue content of dihydrotestosterone in human prostatic hyperplasis is not supranormal. J Clin Invest. 1983; 72(5):1772-7.

\section{Publisher's Note}

Springer Nature remains neutral with regard to jurisdictional claims in published maps and institutional affiliations.

Ready to submit your research? Choose BMC and benefit from:

- fast, convenient online submission

- thorough peer review by experienced researchers in your field

- rapid publication on acceptance

- support for research data, including large and complex data types

- gold Open Access which fosters wider collaboration and increased citations

- maximum visibility for your research: over $100 \mathrm{M}$ website views per year

At $\mathrm{BMC}$, research is always in progress.

Learn more biomedcentral.com/submissions 